\title{
Facial expression in patients with bipolar disorder and schizophrenia in response to emotional stimuli: a partially shared cognitive and social deficit of the two disorders
}

\author{
This article was published in the following Dove Press journal: \\ Neuropsychiatric Disease and Treatment \\ 7 August 2013 \\ Number of times this article has been viewed
}

\author{
Giuseppe Bersani' \\ Elisa Polli' \\ Giuseppe Valeriani' \\ Daiana Zullo' \\ Claudia Melcore' \\ Enrico Capra² \\ Adele Quartini' \\ Pietropaolo Marino' \\ Amedeo Minichino ${ }^{2}$ \\ Laura Bernabei ${ }^{2}$ \\ Maddalena Robiony' \\ Francesco Saverio Bersani',2 \\ Damien Liberati' \\ 'Department of Medico-Surgical \\ Sciences and Biotechnologies, \\ Sapienza University of Rome, Rome, \\ Italy; ${ }^{2}$ Department of Neurology \\ and Psychiatry, Sapienza University \\ of Rome, Rome, Italy
}

\begin{abstract}
Introduction: It has recently been highlighted that patients affected by schizophrenia (SCZ) and those affected by bipolar disorder (BD) undergo gradual chronic worsening of cognitive and social functioning. The objective of the current study was to evaluate and compare (using the Facial Action Coding System [FACS]) the way by which patients with the two disorders experience and display emotions in relation to specific emotional stimuli.

Materials and methods: Forty-five individuals participated in the study: $15 \mathrm{SCZ}$ patients, $15 \mathrm{BD}$ patients, and 15 healthy controls. All participants watched emotion-eliciting video clips while their facial activity was videotaped. The congruent/incongruent feeling of emotions and the facial expression in reaction to emotions were evaluated.

Results: SCZ and BD patients presented similar incongruent emotive feelings and facial expressions (significantly worse than healthy participants); SCZ patients expressed the emotion of disgust significantly less appropriately than BD patients.

Discussion: BD and SCZ patients seem to present a similar relevant impairment in both experiencing and displaying emotions; this impairment may be seen as a behavioral indicator of the deficit of social cognition present in both the disorders. As the disgust emotion is mainly elaborated in the insular cortex, the incongruent expression of disgust of SCZ patients can be interpreted as a further evidence of a functional deficit of the insular cortex in this disease. Specific remediation training could be used to improve emotion and social cognition in SCZ and BD patients.
\end{abstract}

Keywords: schizophrenia, bipolar disorder, facial expression, FACS, social cognition

\section{Introduction}

Schizophrenia (SCZ) and bipolar disorder (BD) are severe and disabling diseases. The main clinical features of the acute phases of the two disorders are very different; however, both disorders are characterized by gradual chronic worsening of cognitive and social functioning. ${ }^{1}$

Cognitive and social impairment of SCZ patients has been widely studied and described in the last decades. ${ }^{2}$ On the other hand, the course of BD has traditionally been viewed as episodic, with symptomatic and functional recovery between mood episodes; ${ }^{3}$ this view has recently been challenged by clinical and epidemiological studies that document how, despite symptomatic improvements, many individuals with $\mathrm{BD}$ experience difficulties in daily functioning also during recovery following mood episodes (for example, there are higher rates of unemployment and disability
Correspondence: Francesco Saverio Bersani,

Department of Neurology and Psychiatry, Sapienza University of Rome, Rome, Italy $\mathrm{Tel}+393405165865$

Fax +390649914728

Email bersani.fs@gmail.com 
among individuals with BD than in the normal population). ${ }^{4-7}$ Cognitive and social impairments have nowadays been found in BD patients even during the euthymic phase of the disease, thus representing trait-associated, rather than stateassociated, characteristics of the disorder. ${ }^{8,9}$

Social cognition (SC) is a multifaceted construct that focuses on how people process information within social contexts; it includes Theory of Mind (ToM), social knowledge/ perception, attributional styles, and emotional processing. ${ }^{10,11}$ A large body of evidence indicates that both patients with $\mathrm{SCZ}$ and those with BD present deficits in some constructs of SC, including ToM and emotional processing, and that these deficits may underlie those areas of the disorders that usually persist despite pharmacological treatments, such as low social functioning, affective flattening, disability, and cognitive deficits. ${ }^{1,12-15}$

It has been repeatedly reported that SCZ patients show characteristic facial activities, such as reduced levels of facial expressivity in reaction to emotional stimuli and during social interactions; this reduction can be seen as a behavioral indicator of emotional processing deficits. ${ }^{12,16,17}$

As BD and SCZ seem to share complex chronic deficits in cognitive functioning and SC that are independent from acute psychopathological manifestations, the aim of the present study is to investigate if and/or to what extent BD patients present reduced levels of facial expressivity, as an index of emotional experiences, similarly to SCZ patients.

\section{Materials and methods}

\section{Participants}

The sample consisted of outpatients recruited at the Alfredo Fiorini Hospital of Terracina, Sapienza University of Rome, and 15 healthy controls. After having signed a written informed consent, patients underwent a structured clinical interview on the model of SCID-I (Structured Clinical Interview for DSM-IV Axis I Disorders) and, according to the criteria of the Diagnostic and Statistical Manual of Mental Disorders, Fourth Edition, Text Revision (DSM-IV-TR), they were divided into two groups: patients with SCZ $(n=15)$ and patients with BD Type I without psychotic symptoms $(n=15$; Table 1). BD patients were in the euthymic phase of the disease while SCZ patients presented a chronic and stable clinical condition; healthy participants were selected to match demographics to the patient group.

Exclusion criteria were: significant concomitant neurological diseases, other Axis I diagnosis, tardive dyskinesia,
Table I Study participants

\begin{tabular}{lllll}
\hline & $\begin{array}{l}\text { Bipolar } \\
\text { disorder }\end{array}$ & Schizophrenia & $\begin{array}{l}\text { Healthy } \\
\text { controls }\end{array}$ & P-value \\
\hline $\begin{array}{l}\text { Number } \\
\text { of patients }\end{array}$ & 15 & 15 & 15 & \\
$\begin{array}{l}\text { Mean age } \\
\text { (years) }\end{array}$ & $48.13 \pm 10.60$ & $45.13 \pm 12.69$ & $41.80 \pm 12.50$ & 0.39 \\
$\begin{array}{l}\text { Sex } \\
7 \text { males, }\end{array}$ & $\begin{array}{l}7 \text { males, } \\
8 \text { females }\end{array}$ & $\begin{array}{l}7 \text { males, } \\
8 \text { females }\end{array}$ & \\
$\begin{array}{l}\text { Education } \\
\text { (years) }\end{array}$ & $11.06 \pm 2.25$ & $10.13 \pm 3.09$ & $13.00 \pm 4.22$ & 0.06 \\
\hline
\end{tabular}

history of abuse of alcohol or other drugs of abuse, hospitalization in the last 12 months, pharmacological treatment with typical antipsychotics, clinical onset within the previous 24 months, Hamilton Depression Rating Scale score $>7$ (for BD patients), young mania rating scale $>11$ (for BD patients), scores $>4$ for "delusions", "conceptual disorganization", and "hallucinations" items of the positive and negative syndrome scale (for SCZ patients).

At the time of the assessment, all patients were on pharmacological treatment as requested by their clinical condition (Table 2).

\section{Facial Action Coding System and video clips}

The Facial Action Coding System (FACS) by Ekman and Friesen ${ }^{18}$ is one of the most widely used instruments for the analysis of facial expression. It is based on an anatomical analysis of facial action through the codification of facial

Table 2 Number of patients treated with each medication

\begin{tabular}{lll}
\hline & $\begin{array}{l}\text { Schizophrenic } \\
\text { patients }\end{array}$ & $\begin{array}{l}\text { Bipolar disorder } \\
\text { patients }\end{array}$ \\
\hline Valproate & 7 & $1 \mathrm{I}$ \\
Aripiprazole & 6 & 2 \\
Paliperidone & 4 & 0 \\
Clozapine & 2 & 0 \\
Risperidone & 2 & 1 \\
Lithium & 1 & 3 \\
Olanzapine & 1 & 2 \\
Quetiapine & $\mathrm{I}$ & 2 \\
Paroxetine & $\mathrm{I}$ & 0 \\
Clomipramine & $\mathrm{I}$ & 2 \\
Fluvoxamine & $\mathrm{I}$ & 0 \\
Escitalopram & $\mathrm{I}$ & 0 \\
Bupropione & 0 & 1 \\
Gabapentin & 0 & 1 \\
Fluoxetine & 0 & 1 \\
Duloxetine & 0 & 1 \\
Lamotrigine & 0 & 0 \\
\hline & &
\end{tabular}


expression in 44 "action units" (AUs; Figure 1). AUs are anatomically defined; they represent the basic repertory of human facial expressions. Using the FACS, the variety of facial movements can be observed objectively.

The FACS investigator's guide ${ }^{19}$ codes the exact combinations of AUs that should be observed in response to each emotional stimulus (Figure 2).

The use of video clips to elicit specific emotions has a long history in clinical psychology and psychiatry; ${ }^{20}$ Gross et al systematized this issue selecting and validating 16 films that successfully elicited amusement, anger, contentment, disgust, sadness, surprise, fear, and a neutral state. ${ }^{21}$ Video clip details are given in Table 3 .

\section{Study design}

All patients watched video clips designed to elicit significant and specific emotions. The facial expression of each patient in response to the vision of the films was video recorded. These video clips, all in Italian, were watched by the three groups of subjects in the same order, according to the protocol established by Gross ${ }^{21}$ and according to the protocol of a previous study by our research team: ${ }^{22}$ video $1=$ neutral; video 2 = amusement; video 3 = fear; video $4=$ surprise; video $5=$ anger; video $6=$ sadness; video $7=$ disgust; video $8=$ amusement.

Between single video clips, patients were asked to fill out a post film questionnaire to indicate what emotion

\begin{tabular}{|c|c|c|}
\hline AU number & FACS name & Muscular basis \\
\hline 1 & Inner brow raiser & Frontalis, pars medialis \\
\hline 2 & Outer brow raiser & Frontalis, pars lateralis \\
\hline 4 & Brow lowerer & Depressor glabellae; depressor supercilli; corrugator \\
\hline 5 & Upper lid raiser & Levator palpebrae superioris \\
\hline 6 & Cheek raiser & Orbicularis oculi, pars orbitalis \\
\hline 7 & Lid tightener & Orbicularis oculi, pars palebralis \\
\hline 8 & Lips toward each other & Orbicularis oris \\
\hline 9 & Nose wrinkler & Levator labii superioris, alaeque nasi \\
\hline 10 & Upper lip raiser & Levator labii superioris, caput infraorbitalis \\
\hline 11 & Nasolabial furrow deepener & Zygomatic minor \\
\hline 12 & Lip corner puller & Zygomatic major \\
\hline 13 & Cheek puffer & Caninus \\
\hline 14 & Dimpler & Buccinnator \\
\hline 15 & Lip corner depressor & Triangularis \\
\hline 16 & Lower lip depressor & Depressor labii \\
\hline 17 & Chin raiser & Mentalis \\
\hline 18 & Lip puckerer & Incisivii labii superioris; incisivii labii inferioris \\
\hline 20 & Lip stretcher & Risorius \\
\hline 22 & Lip funneler & Orbicularis oris \\
\hline 23 & Lip tightener & Orbicularis oris \\
\hline 24 & Lip pressor & Orbicularis oris \\
\hline 25 & Lips part & Depressor labii, or relaxation of mentalis or orbicularis oris \\
\hline 26 & Jaw drop & Masetter; temporal and internal pterygoid relaxed \\
\hline 27 & Mouth stretch & Pterygoids; digastric \\
\hline 28 & Lip suck & Orbicularis oris \\
\hline 38 & Nostril dilator & Nasalis, pars alaris \\
\hline 39 & Nostril compressor & Nasalis, pars transversa and depressor septi nasi \\
\hline 41 & Lid droop & Relaxation of levator palpebrae superioris \\
\hline 42 & Slit & Orbicularis oculi \\
\hline 43 & Eyes closed & Relaxation of levator palpebrae superioris \\
\hline 44 & Squint & Orbicularis oculi, pars palpebralis \\
\hline 45 & Blink & $\begin{array}{l}\text { Relaxation of levator palpebrae and contraction of orbicularis oculi, } \\
\text { pars palpebralis }\end{array}$ \\
\hline 46 & Wink & Orbicularis oculi \\
\hline
\end{tabular}

Figure I Action units.

Abbreviations: AU, action units; FACS, Facial Action Coding System. 


\begin{tabular}{|c|c|c|}
\hline Emotion & Prototypes & Major variants \\
\hline & $\begin{array}{l}1+2+5 B+26 \\
1+2+5 B+27\end{array}$ & $\begin{array}{l}1+2+5 B \\
1+2+26\end{array}$ \\
\hline Surprise & & $\begin{array}{l}1+2+27 \\
5 B+26 \\
5 B+27\end{array}$ \\
\hline Fear & $\begin{array}{l}1+2+4+5^{\star}+20^{\star}+25,26, \text { or } 27 \\
1+2+4+5^{\star}+25,26, \text { or } 27\end{array}$ & $\begin{array}{l}1+2+4+5^{*}+\mathrm{L} \text { or } \mathrm{R} 20^{*}+25,26, \text { or } 27 \\
1+2+4+5^{\star} \\
1+2+5 \mathrm{E}, \text { with or without } 25,26,27 \\
5^{\star}+20^{\star} \text { with or without } 25,26,27\end{array}$ \\
\hline Happy & $\begin{array}{l}6+12^{*} \\
12 C / D\end{array}$ & \\
\hline Sadness & $\begin{array}{l}1+4+11+15 \text { B with or without } 54+64 \\
1+4+15^{\star} \text { with or without } 54+64 \\
6+15^{\star} \text { with or without } 54+64\end{array}$ & $\begin{array}{l}1+4+11 \text { with or without } 54+64 \\
1+4+15 B \text { with or without } 54+64 \\
1+4+15 B+17 \text { with or without } 54+64 \\
11+15 B \text { with or without } 54+64 \\
11+17\end{array}$ \\
\hline & \multicolumn{2}{|c|}{25 or 26 may occur with all prototypes or major variants } \\
\hline Disgust & $\begin{array}{l}9 \\
9+16+15,26 \\
9+17 \\
10^{\star} \\
10^{\star}+16+25,26 \\
10+17\end{array}$ & \\
\hline Anger & $\begin{array}{l}4+5^{\star}+7+10^{\star} 22+23+25,26 \\
4+5^{\star}+7+10^{\star}+23+25,26 \\
4+5^{\star}+7+23+25,26 \\
4+5^{\star}+7+17+23 \\
4+5^{\star}+7+17+24 \\
4+5^{\star}+7+23 \\
4+5^{\star}+7+24\end{array}$ & $\begin{array}{l}\text { Any of the prototypes without any one of the following } \\
\text { AUs: } 4,5,7 \text {, or } 10\end{array}$ \\
\hline
\end{tabular}

Figure 2 Expected action units for each emotion.

Notes: *In this combination the AU may be at any intensity level. A-E represent the intensity of the action: A, Trace; B, Slight; C, Marked or Pronounced; D, Severe or Extreme; E, Maximum.

Abbreviations: $A U$, action units; $R$, actions only on the right side of the face; L, actions only on the left side of the face.

they experienced in relation to the video (Table 4). ${ }^{22}$ Each response to the questionnaire was then scored in relation to the expected emotion.

Two different reports were produced. In the report of concordant responses, a score of 1 was given for each emotional report concordant with the expected emotion and a score of 0 was given if the patient reported to not have felt any emotion (neutrality) or to have felt an emotion different from that expected. Scores could range between a minimum of 0 and a maximum of 8 ; for example, patients obtained an 8 when they reported concordant emotions in response to all the 8 video clips. In the report of discordant responses, a score of 1 was given for each emotional report discordant with the expected emotion associated with the video clip and 0 if the patient reported to not have felt any emotion (neutrality). Scores could range between a minimum of 0 and a maximum of 8 ; for example, patients obtained the score 8 when they reported wrong emotions in response to all the 8 video clips.

At the end of the film session, the mimic reactions to the video clips were coded following the indications of the FACS investigator's guide. ${ }^{19}$ The same three examiners (EP, GV, DL)

Table 3 Video clips used to elicit emotions

\begin{tabular}{lll}
\hline Video & Description & $\begin{array}{c}\text { Elicited emotion } \\
\text { (minute:second) }\end{array}$ \\
\hline Video I: Color bars & Color bars & Neutrality \\
Video 2: When Harry Met Sally & Discussion of orgasm in café & Amusement \\
Video 3: The Shining & Boy playing in hallway & Fear \\
Video 4: Capricorn One & Agents burst through door & Surprise \\
Video 5: Cry Freedom & Police abuse protesters & Anger \\
Video 6: The Champ & Boy cries at father's death & Sadness \\
Video 7: Pink Flamingos & Person eats dog feces & Disgust \\
Video 8: Roberto Benigni and Massimo & Comedy routine & Amusement \\
Troisi video interview & & $2: 36$ \\
\hline
\end{tabular}


Table 4 Post film questionnaire

\begin{tabular}{lllllllll}
\hline Emotion & \multicolumn{1}{l}{ Video } & & & & & & \\
\cline { 2 - 7 } & $\mathbf{I}$ & $\mathbf{2}$ & $\mathbf{3}$ & $\mathbf{4}$ & $\mathbf{5}$ & $\mathbf{6}$ & $\mathbf{7}$ & $\mathbf{8}$ \\
\hline Fear & & & & & & & & \\
Sadness & & & & & & & & \\
Happiness & & & & & & & & \\
Surprise & & & & & & & & \\
Anger & & & & & & & & \\
Disgust & & & & & & & & \\
Neutrality & & & & & & & & \\
\hline
\end{tabular}

evaluated all video registrations. The three examiners previously attended a specific 3-day workshop organized by the Centro Ricerche FACS Onlus (CRF; FACS research center) at the University of Trieste. For the scoring it was considered the specific expected emotion associated to the video and the combination of AUs observed in response. Since each video was evocative of only one specific emotion, specific combinations of AUs were expected in relation to each video (Figure 2). If one of the expected combinations of AUs occurred, the examiners assigned the score 1 ; if the expected combinations did not occur the examiners assigned the score 0 (this scoring was repeated for each movie clip); for example, patients obtained the score 8 when they presented the expected facial expression (Figures 1 and 2) in response to all eight video clips.

\section{Statistical analysis}

The data were analyzed using SPSS software version 20 (IBM Corporation, Armonk, NY, USA). One-way univariate analysis of variance (ANOVA) was used to compare sociodemographic data of participants.

In addition to descriptive statistics, one-way univariate ANOVA was performed to compare the mean scores of participants divided into diagnosis groups. As the diagnosis factor had more than two levels, post-hoc tests were calculated using the Bonferroni test.

Chi-squared and Fisher's exact test were used to compare the right or wrong facial expression in reaction to emotional stimuli of $\mathrm{BD}$ and $\mathrm{SCZ}$ patients.

\section{Results \\ Post film questionnaire - concordant responses}

One-way ANOVA determined statistically significant differences between group means ( $\mathrm{F} 2=25.39, P<0.01)$. Mean score \pm standard deviation of the report of concordant responses was $4.13 \pm 1.50$ for $\mathrm{SCZ}$ patients, $4.93 \pm 1.75$ for BD patients, and $7.53 \pm 0.51$ for healthy controls. Comparing between groups with the post-hoc Bonferroni test revealed that healthy controls had significantly higher scores than both SCZ (difference of means $=3.40 ; P<0.01$ ) and BD patients (difference of means $=2.60 ; P<0.01)$. There were not significant differences between SCZ and BD patients ( $P=0.34$; Figure 3 ).

\section{Post film questionnaire - discordant responses}

One-way ANOVA determined statistically significant differences between group means $(\mathrm{F} 2=17.91, P<0.01)$. Mean scores \pm standard deviation of the report of discordant responses were $2.20 \pm 1.26$ for SCZ patients, $1.46 \pm 1.24$ for BD patients, and $0.00 \pm 0.00$ for healthy controls. Comparing between groups using the post-hoc Bonferroni test showed that healthy controls had significantly lower scores than both SCZ (difference of means $=-2.20 ; P<0.01$ ) and BD patients (difference of means $=-1.46 ; P<0.01)$. There were no significant differences between SCZ and BD patients $(P=0.17$; Figure 4$)$.

\section{Facial expressions}

One-way ANOVA determined statistically significant differences between group means ( $\mathrm{F} 2=33.42, P<0.01)$. Mean FACS score was $3.26 \pm 1.53$ for $\mathrm{SCZ}$ patients, $5.00 \pm 1.51$ for BD patients, and $7.13 \pm 0.63$ for healthy controls. Comparing between groups using the post-hoc Bonferroni test showed that the FACS score of SCZ patients was significantly lower than $\mathrm{BD}$ (difference of means $=-1.73 ; P<0.01$ ) and healthy controls (difference of means $=-3.86 ; P<0.01$ ). BD patients and healthy controls also had significantly different scores (different of means $=2.13 ; P<0.01 ;$ Figure 5$)$.

\section{Facial expression in reaction to emotional stimuli in BD and SCZ patients}

According to the FACS investigator's guide, all BD and SCZ patients showed congruent facial expression in response to

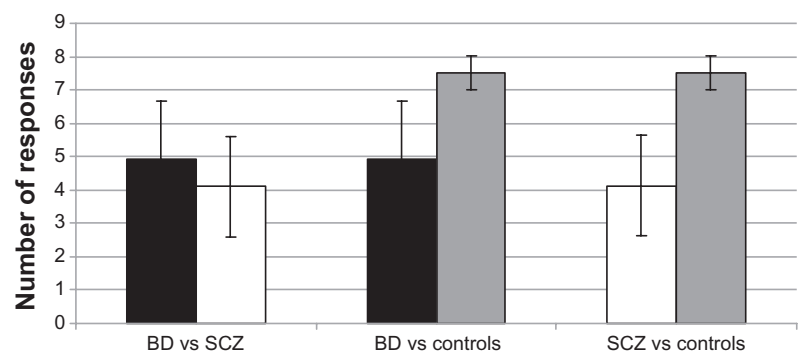

Figure 3 Mean number of concordant responses in BD, SCZ, and control groups. Note: $* P<0.05$.

Abbreviations: BD, bipolar disorder; SCZ, schizophrenic; vs, versus. 


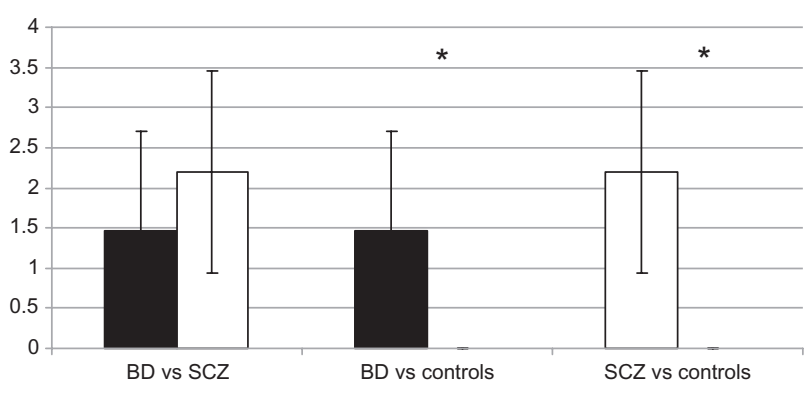

Figure 4 Mean number of discordant responses in BD, SCZ, and control groups. Note: $* P<0.05$.

Abbreviations: BD, bipolar disorder; SCZ, schizophrenic; vs, versus.

neutral stimuli, seven BD and two SCZ $(P=0.10)$ patients showed congruent facial expressions in response to fear stimuli, three $\mathrm{BD}$ and four SCZ $(P=0.45)$ patients showed congruent facial expressions in response to surprise stimuli, five $\mathrm{BD}$ and three $\mathrm{SCZ}(P=0.68)$ patients showed congruent facial expression in response to anger stimuli, nine $\mathrm{BD}$ and four $\mathrm{SCZ}(P=0.13)$ patients showed congruent facial expression in response to sadness stimuli, $14 \mathrm{BD}$ and seven $\mathrm{SCZ}(P=0.01)$ patients showed congruent facial expressions in response to disgust stimuli, $18 \mathrm{BD}$ and $14 \mathrm{SCZ}(P=0.43)$ patients showed congruent facial expression in response to amusement stimuli (amusement stimuli were showed twice; Table 5).

\section{Discussion}

To our knowledge, this is the first study investigating and comparing the facial expression of patients with SCZ and BD using the FACS system.

As expected, healthy controls showed more appropriate emotional experience and facial expression than patient groups (Figures 3-5). This finding partially confirms the hypothesis that BD patients, as well as SCZ patients, present reduced levels of facial expressivity presumably attributable to deficit of emotional processing and SC.

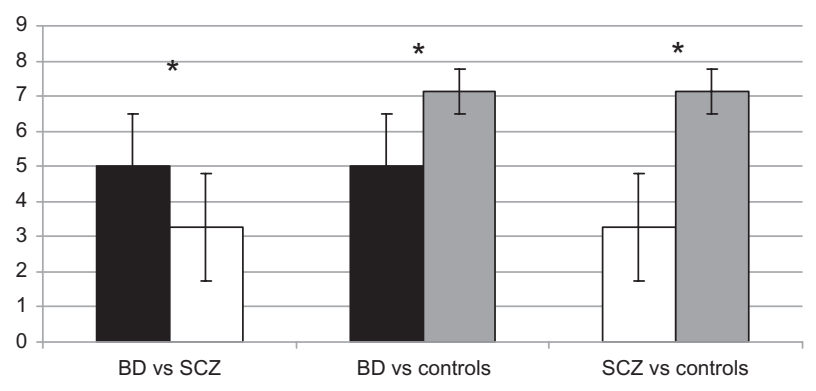

Figure 5 Mean FACS scores in BD, SCZ, and control groups. Note: $* P<0.05$.

Abbreviations: BD, bipolar disorder; FACS, Facial Action Coding System; SCZ, schizophrenic; vs, versus.
Table 5 Patients that expressed congruent facial expression in response to video clips stimuli

\begin{tabular}{|c|c|c|c|c|c|}
\hline & \multicolumn{2}{|c|}{$\begin{array}{l}\text { Bipolar disorder } \\
\text { group }\end{array}$} & \multicolumn{2}{|c|}{$\begin{array}{l}\text { Schizophrenic } \\
\text { group }\end{array}$} & \multirow[t]{2}{*}{$P$-value } \\
\hline & $\mathbf{N}$ & $\%$ & $\mathbf{N}$ & $\%$ & \\
\hline Neutrality & 15 & $100 \%$ & 15 & $100 \%$ & \\
\hline Amusement & 9 & $60 \%$ & 6 & $40 \%$ & 0.46 \\
\hline Fear & 7 & $46.6 \%$ & 2 & $13.3 \%$ & 0.10 \\
\hline Surprise & 3 & $20 \%$ & 4 & $26.6 \%$ & 0.45 \\
\hline Anger & 5 & $33.3 \%$ & 3 & $20 \%$ & 0.68 \\
\hline Sadness & 9 & $60 \%$ & 4 & $26.6 \%$ & 0.13 \\
\hline Disgust & 14 & $93.3 \%$ & 7 & $46.6 \%$ & $0.01 *$ \\
\hline Amusement & 9 & $60 \%$ & 8 & $53.3 \%$ & 1.00 \\
\hline
\end{tabular}

SCZ patients presented a more compromised facial expression than BD patients (Figure 5). This issue is consistent with existing data: previous studies already found that deficits in expressing emotions are often present in SCZ patients and correlate with neuroleptics treatment ${ }^{23}$ and the intensity of negative symptoms (in particular with the affective flattening). ${ }^{24}$

The only significant difference between patients' facial expression in reaction to video clips was found for the expression of disgust (Table 5): one BD and eight SCZ patients $(P=0.01)$ showed incongruent facial expression in response to disgust stimuli represented by scenes from the "Pink Flamingos" film. This issue is consistent with a previous study of Kholer et $\mathrm{al}^{25}$ where it was found that $\mathrm{SCZ}$ patients had more severe impairment in relation to specific emotions such as amusement, fear, and disgust.

The deficit in the expression of disgust highlights some possible new evidence with respect to the relationship between neuroanatomy of SCZ. Functional neuroimaging research demonstrated that facial expressions of disgust engage the insular cortex more consistently than other facial expressions $;{ }^{26}$ furthermore, several studies found that lesions in the insular cortex compromise the capacity of recognizing and expressing the disgust emotion. ${ }^{27-29}$

The insular cortex is believed to be involved in consciousness and plays a role in diverse functions including perception, motor control, self-awareness, cognitive functioning, and interpersonal experience. ${ }^{30-33}$ There is an increasingly amount of data suggesting possible hypofunctioning of the insular cortex in SCZ patients, ${ }^{34,35}$ while there is no data about its possible involvement in BD. As the disgust emotion is mainly elaborated in the insular cortex, the incongruent expression of disgust of SCZ patients could be seen as further evidence of a deficit of the functionality of the insular cortex in SCZ. 
The results of the post film questionnaires indicated that $\mathrm{BD}$ and $\mathrm{SCZ}$ patients seem to present similar relevant impairment in recognizing and experiencing emotions: there was no significant difference between the results of the two groups of patients (both of them having significantly worse results than healthy controls; Figures 3 and 4). Difficulty in recognizing and experiencing emotions observed through the facial expression in patients could reflect the impairment in SC recently described in both $\mathrm{SCZ}$ and $\mathrm{BD} .^{1,14}$ Frommann et al, Marsh et al, and Lewandowski et al all found that emotional processing and social cognition in SCZ can be improved through targeted remediation training. ${ }^{36-38}$ This training could potentially be used to improve the global functioning of both $\mathrm{SCZ}$ and $\mathrm{BD}$ patients in addition to medications and psychotherapies.

\section{Limitations}

The small number of participants is a major limitation of the study; for this reason, the results should be considered preliminary. Moreover, the coders were not blinded about the status of patients.

The choice to reduce the power of FACS to a binary number (expression prototype present or absent) makes it a less sensitive measure and as such different degrees of more refined and subtle facial movements could not be evaluated. This step was deemed necessary, however, as it reduced the possibility of codification bias.

Further studies are needed to further assess differences and similarities in emotional responses in $\mathrm{BD}, \mathrm{SCZ}$, and other psychiatric diseases.

\section{Disclosure}

The authors report no conflicts of interest in this work.

\section{References}

1. Donohoe G, Duignan A, Hargreaves A, et al. Social cognition in bipolar disorder versus schizophrenia: comparability in mental state decoding deficits. Bipolar Disord. 2012;14(7):743-748.

2. Green MF. Cognitive impairment and functional outcome in schizophrenia and bipolar disorder. J Clin Psychiatry. 2006;67(10):e12.

3. Trede K, Salvatore P, Baethge C, Gerhard A, Maggini C, Baldessarini RJ. Manic-depressive illness: evolution in Kraepelin's Textbook, 1883-1926. Harv Rev Psychiatry. 2005;13(3):155-178.

4. Kogan JN, Otto MW, Bauer MS, et al; STEP-BD Investigators. Demographic and diagnostic characteristics of the first 1000 patients enrolled in the Systematic Treatment Enhancement Program for Bipolar Disorder (STEP-BD). Bipolar Disord. 2004;6(6):460-469.

5. Tohen M, Zarate CA, Hennen J, et al. The McLean-Harvard FirstEpisode Mania Study: prediction of recovery and first recurrence. Am J Psychiatry. 2003;160(12):2099-2107.

6. Kessler RC, Akiskal HS, Ames M, et al. Prevalence and effects of mood disorders on work performance in a nationally representative sample of US workers. Am J Psychiatry. 2006;163(9):1561-1568.
7. Morris CD, Miklowitz DJ, Wisniewski SR, Giese AA, Thomas MR, Allen MH. Care satisfaction, hope, and life functioning among adults with bipolar disorder: data from the first 1000 participants in the Systematic Treatment Enhancement Program. Compr Psychiatry. 2005;46(2): 98-104.

8. Martínez-Arán A, Vieta E, Colom F, et al. Cognitive impairment in euthymic bipolar patients: implications for clinical and functional outcome. Bipolar Disord. 2004;6(3):224-232.

9. de Almeida Rocca CC, de Macedo-Soares MB, Gorenstein C, et al. Social dysfunction in bipolar disorder: pilot study. Aust N Z J Psychiatry. 2008;42(8):686-692.

10. Penn DL, Sanna LJ, Roberts DL. Social cognition in schizophrenia: an overview. Schizophr Bull. 2008;34(3):408-411.

11. Green MF, Horan WP. Social Cognition in schizophrenia. Curr Dir Psychol Sci. 2010;19(4):243-248.

12. Shamay-Tsoory SG, Shur S, Harari H, Levkovitz Y. Neurocognitive basis of impaired empathy in schizophrenia. Neuropsychology. 2007;21(4):431-438.

13. Sparks A, McDonald S, Lino B, O’Donnell M, Green MJ. Social cognition, empathy and functional outcome in schizophrenia. Schizophr Res. 2010;122(1-3):172-178.

14. Baez S, Herrera E, Villarin L, et al. Contextual social cognition impairments in schizophrenia and bipolar disorder. PLoS ONE. 2013;8(3):e57664

15. Bersani FS, Capra E, Minichino A, et al. Factors affecting interindividual differences in clozapine response: a review and case report. Hum Psychopharmacol. 2011;26(3):177-187.

16. Aghevli MA, Blanchard JJ, Horan WP. The expression and experience of emotion in schizophrenia: a study of social interactions. Psychiatry Res. 2003;119(3):261-270.

17. Polli E, Bersani FS, De Rose C, et al. Facial Action Coding System (FACS): an instrument for the objective evaluation of facial expression and its potential applications to the study of schizophrenia. Riv Psichiatr. 2012;47(2):126-138. Italian.

18. Ekman P, Friesen WV. Facial Action Coding System: a technique for the measurement of facial movement. Palo Alto: Consulting Psychologists Press; 1978.

19. Ekman P, Friesen W, Hager JC. Facial Action Coding System Investigator's Guide. Palo Alto; Consulting Psychologists Press; 1978.

20. Philippot $P$. Inducing and assessing differentiated emotion-feeling states in the laboratory. Cogn Emot. 1993;7(2):171-193.

21. Gross JJ, Levenson RW. Emotion elicitation using films. Cogn Emot. 1995;9(1):87-108.

22. Bersani G, Bersani FS, Valeriani G, et al. Comparison of facial expression in patients with obsessive-compulsive disorder and schizophrenia using the Facial Action Coding System: a preliminary study. Neuropsychiatr Dis Treat. 2012;8:537-547.

23. Schneider F, Ellgring H, Friedrich J, et al. The effects of neuroleptics on facial action in schizophrenic patients. Pharmacopsychiatry. 1992;25(5):233-239.

24. Blanchard JJ, Sayers SL, Collins LM, Bellack AS. Affectivity in the problem-solving interactions of schizophrenia patients and their family members. Schizophr Res. 2004;69(1):105-117.

25. Kohler CG, Martin EA, Stolar N, et al. Static posed and evoked facial expressions of emotions in schizophrenia. Schizophr Res. 2008;105(1-3):49-60.

26. Phillips ML, Young AW, Scott SK, et al. Neural responses to facial and vocal expressions of fear and disgust. Proc Biol Sci. 1998;265(1408): 1809-1817.

27. Sprengelmeyer R, Young AW, Calder AJ, et al. Loss of disgust. Perception of faces and emotions in Huntington's disease. Brain. 1996;119(Pt 5):1647-1665.

28. Sprengelmeyer R, Young AW, Pundt I, et al. Disgust implicated in obsessive-compulsive disorder. Proc Biol Sci. 1997;264(1389): 1767-1773.

29. Calder AJ, Keane J, Manes F, Antoun N, Young AW. Impaired recognition and experience of disgust following brain injury. Nat Neurosci. 2000;3(11):1077-1078. 
30. Bamiou DE, Musiek FE, Luxon LM. The insula (Island of Reil) and its role in auditory processing. Literature review. Brain Res Brain Res Rev. 2003;42(2):143-154.

31. Craig AD. How do you feel - now? The anterior insula and human awareness. Nat Rev Neurosci. 2009;10(1):59-70.

32. Baliki MN, Geha PY, Apkarian AV. Parsing pain perception between nociceptive representation and magnitude estimation. J Neurophysiol. 2009;101(2):875-887.

33. Ortigue S, Grafton ST, Bianchi-Demicheli F. Correlation between insula activation and self-reported quality of orgasm in women. Neuroimage. 2007;37(2):551-560.

34. Shepherd AM, Matheson SL, Laurens KR, Carr VJ, Green MJ. Systematic meta-analysis of insula volume in schizophrenia. Biol Psychiatry. 2012;72(9):775-784.
35. Linnman C, Coombs G, Goff DC, Holt DJ. Lack of insula reactivity to aversive stimuli in schizophrenia. Schizophr Res. 2013;143(1): $150-157$.

36. Frommann N, Streit M, Wölwer W. Remediation of facial affect recognition impairments in patients with schizophrenia: a new training program. Psychiatry Res. 2003;117(3):281-284.

37. Marsh PJ, Green MJ, Russell TA, McGuire J, Harris A, Coltheart M. Remediation of facial emotion recognition in schizophrenia: functional predictors, generalisability and durability. Am J Psych Rehab. 2010;13(2):143-170.

38. Lewandowski KE, Eack SM, Hogarty SS, Greenwald DP, Keshavan MS. Is cognitive enhancement therapy equally effective for patients with schizophrenia and schizoaffective disorder? Schizophr Res. 2011;125(2-3):291-294.

\section{Publish your work in this journal}

Neuropsychiatric Disease and Treatment is an international, peerreviewed journal of clinical therapeutics and pharmacology focusing on concise rapid reporting of clinical or pre-clinical studies on a range of neuropsychiatric and neurological disorders. This journal is indexed on PubMed Central, the 'PsycINFO' database and CAS.
The manuscript management system is completely online and includes a very quick and fair peer-review system, which is all easy to use. Visit http://www.dovepress.com/testimonials.php to read real quotes from published authors. 